\title{
Eriqinal Article
}

\section{The economic standpoint of referral system at using tertiary hospital services in Iran}

\author{
Samad Rouhani ${ }^{1}$ Sekineh Alipoor Landy ${ }^{2 *}$
}

1. Associate Professor, Department of Public Health, Health Sciences Research Center, Mazandaran University of Medical Sciences, Sari, Iran.

2. Student Research Committee, Mazandaran University of Medical Sciences, Sari, Iran.

*Correspondence to: Sekineh Alipoor Landy

ghalipoor67@gmail.com

\section{Abstract}

Background and purpose: Although, economically, referral systems make utilization of health facilities at different levels sound, in many countries caretakers often bypass primary care facilities that are regularly costlier for caretakers and health care systems. The main objective of the current study was to assess the utilization of hospital services with more emphasis on economic point of view.

Materials and methods: The present study was a facility-based cross-sectional study. A researcher developed questionnaire was used to collect the data. The samples were randomly selected and interviewed on their consent. SPSS Software was also used to analyze the collected data through Chi-2, correlation, and t-test.

Results: Just 29.4 percent of the attendees to the hospital were carrying out a referral slip from their family medicine. Five variables including type of care, type of attending, appointment arrangement, satisfaction with family medicine, and vising family medicine were statistically analyzed and found significantly related to carrying referral slip.

Conclusion: Because of dysfunction of referral system, Iran's health care system was found to be far from achieving economic advantages of a referral based WHO District Health System. It is actually an inappropriate use of limited health resources in a country like Iran that seriously suffers from shortage of financial and health system resources. This is likely due to deficiencies in the components of its referral system, therefore, a full revision of current reforms and appropriate remedies for deficiencies in the components of referral system was found to be in top priority in Iran.

Keywords: Gatekeeping; Referral; Family Practitioner; Hospital

Citation: Rouhani S, Alipoor Landy S. The economic standpoint of referral system at using tertiary hospital services in Iran. Iran J Health Sci. 2017; 5(1):38-48 


\section{Introduction}

As a basic human right, all people deserve to have access to health care services regardless of their socioeconomic differences (1). No individual country even in developed world could provide such services equitably without a rational and appropriately organized health care system. In most countries, there are two major types of health facilities, primary care facilities and hospitals. Health care systems are often designed to encourage caretakers to seek care first at the primary care level and then be referred, if necessary, to a higher level of care i.e. hospitals (2). If this reflects actual care seeking behavior, then healthcare costs for the caretaker will be minimized (3). In many countries, however, caretakers often bypass primary care facilities and seek care directly at referral care hospitals for illnesses that could be easily treated at the primary care facilities (4). This can overburden the referral facilities, and is often costlier for the caretaker and the healthcare system. Different factors such as behavioral, cultural, and systemic factors have been mentioned that could influence compliance with referral system. Caretakers may be faced with a number of barriers before they comply with referral advice. Such barriers can be financial, geographic, and cultural. The relative importance of these barriers is usually unknown to public health planners in most countries implementing integrated healthcare services; consequently, interventions to improve caretaker compliance with referral are difficult to develop. Health workers may also have difficulty in complying with guidelines for referral especially in rural areas where caretakers may be faced with many communication and transportation barriers (5). A well-functioning referral system is fundamental to primary healthcare (PHC) delivery. Through referrals, primary care facilities save lives and provide prompt responses to emergency situations; they do this by helping people obtain access to higher levels of care, particularly at district level (6). Based on WHO District Health System (DHS) model, ideally, the two components of health systems, primary care facilities and hospitals, should complement each other; the health center level offers proximity care using relatively low level technology, while the district hospital takes care of patients referred by the health centers $(7,8)$. Thus, the referral system is an important element of this organization. An effective referral system contributes to giving a high quality of care and results in good costcontainment because it restrains overtreatment (9), hence a well-functioning referral system is fundamental to primary healthcare delivery. Nevertheless, referral systems are frequently dysfunctional (10). Effective referral systems are instrumental in improving quality of care, decreasing healthcare expenditures and improving health outcomes (11). According to the Aday and Andersen model for access and utilization of care, multiple factors may influence utilization of health services. Such factors may include characteristics of the population at risk and characteristics of the healthcare delivery system (12-16). An effective referral system ensures a close relationship between all levels of the health system and helps to ensure people receive the best possible care closest to home. It also assists in making cost-effective use of hospitals 
and primary healthcare services. In many developing countries, a high proportion of clients seen at the outpatient clinics at secondary facilities could be appropriately looked after at primary healthcare centers at lower overall cost to the client and the health system. The design and functioning of a referral system in any individual country will be influenced by many factors such as capabilities of lower levels, availability of specialized personnel, training capacity, organizational arrangements, cultural issues, political issues, traditions, population size, and density, terrain and distances between urban centers, pattern and burden of disease, and demand for and ability to pay for referral care as either health systems determinants or general determinants (13-17). The aim of this research was then to investigate socio-economic and health seeking behavior of caretakers at using hospital services in Iran.

\section{Materials and Methods}

The present research was a facility-based crosssectional study. Given the economic advantages of referral system, the aim of the current study was to investigate the pattern of referral hospital utilization at a provincial tertiary teaching hospital, Imam Khomeini Hospital, affiliated to Mazandaran University of Medical Sciences in northern part of Iran. This hospital is a typical hospital in terms of its ownership, rules and regulations, financing, payment mechanism, and price of services. Then, it could be a representative hospital for the majority of state-owned hospitals in Iran. Tertiary hospitals at the third level of healthcare delivery system usually use more advanced technology, sub-specialists, and hence are more expensive. To make the utilization of such expensive and sophisticated facilities economically sound, the minimum expectation is that attendance should at least be subject to carrying out a referral slip. A researcherdeveloped questionnaire was used to extract data from attendees to hospital at admission department. In developing this questionnaire and improving its construct validity, relevant to the objectives and variables of study, literature as well as informed opinion was consulted. Before the main study, the provisional draft of questionnaire was piloted among a limited number of patients, and based on that, some corrections were made to improve the content validity of the questionnaire. Using the sample size equation, 96 cases were required; however, for improving the results, we decided to approach a bigger sample size of about 50 percent. Then, 149 caretakers were randomly selected and interviewed on their consent. The respondents were selected on random basis to reduce the biases and to provide more representative sample. The collected data was coded, and an excel file was produced. Then, SPSS Software was used for analyzing the collected data through Chi-2, correlation, and ttest as inferential statistical measures.

\section{Results}

In the current study, 149 patients attending Imam Khomeini Hospital, a typical tertiary teaching hospital, were interviewed. The data has shown that the highest frequency of patients (29.1\%) was related to 25-35 age group, where this figure for the age group under 15 years old with the lowest rate was $4.1 \%$. Most attendees in this study were female $(58.8 \%)$. In terms of marital status, $67.4 \%$ of the respondents were 
married. At the same time, except for $11.3 \%$, the respondents had some degree of education ranging from elementary to academic education of above the degree. Regarding job category, housekeeping was the prevalent category with $60.3 \%$ frequency, and $66.2 \%$ of the respondents have classified themselves as being fit to average economic group. Majority of the respondents $(51.5 \%)$ were from urban areas. In addition, $65.9 \%$ of the respondents came from the area of less than 1 hour distance from hospital and $81.7 \%$ of the patients have used public transport as means to attend the hospital. Out of these studied population, just $29.4 \%$ attended the hospital carrying a referral slip from their family practitioner. In the following table, some socio-economic characteristics of the hospital attendees are also presented.

Table 1. Socioeconomic characteristics of respondents in a typical tertiary teaching hospital in Sari-Iran

\begin{tabular}{lll}
\hline Variable & Frequency & Percentage \\
\hline Age group: & & \\
15 years $<$ & 6 & 4.4 \\
16-25 years & 22 & 16.3 \\
26-35 years & 40 & 29.6 \\
36-45 years & 37 & 27.4 \\
46 years > & 30 & 22.2 \\
Literacy: & & \\
Literate & 110 & 88.7 \\
Illiterate & 14 & 11.3 \\
Location: & & \\
Urban & 70 & 51.5 \\
Slum area & 62 & 45.6 \\
Rural & 4 & 2.9 \\
Distance: & & \\
One hour $<$ & 89 & 65.9 \\
One hour $>$ & 46 & 34.1 \\
Type of transport: & & \\
Public & 107 & 81.7 \\
Private & 24 & 18.3 \\
Job: & & \\
Employed & & 39.7 \\
Housekeepers or not & 79 & 60.3 \\
working & & \\
Economic status: & & 24.6 \\
Weak & 32 & 9.2 \\
Average & 86 & \\
Good & 12 & \\
\hline & & \\
\hline & & \\
\hline & & \\
\hline
\end{tabular}

As is indicated in Table 1, the respondents were mostly adults, literate with economic statues of average or below average. None of the variables being presented in Table 1 were 
significantly associated with following the referral guideline. The health seeking behavior of respondents and relevant characteristics are also presented in Table 2 .

Table 2. Health seeking behavior and relevant characteristics of caretakers in a typical tertiary teaching hospital in Sari-Iran

\begin{tabular}{|c|c|c|}
\hline \multirow{2}{*}{$\begin{array}{l}\text { Variable } \\
\text { Type of hospital attending: }\end{array}$} & Frequency & Percentage \\
\hline & & \\
\hline $\begin{array}{l}\text { Type of nospital attending: } \\
\text { Emergency by ambulance }\end{array}$ & 6 & 4.4 \\
\hline Emergency without ambulance & 62 & 45.6 \\
\hline Non-emergency & 68 & 50.0 \\
\hline \multicolumn{3}{|l|}{ Reason for attending hospital: } \\
\hline Outpatient & 64 & 47.1 \\
\hline Inpatient & 72 & 52.9 \\
\hline \multicolumn{3}{|l|}{ Severity of disease: } \\
\hline Slight & 7 & 5.2 \\
\hline Moderate & 69 & 51.1 \\
\hline Severe & 59 & 43.7 \\
\hline \multicolumn{3}{|l|}{ Arranging appointment: } \\
\hline Yes & 40 & 30.1 \\
\hline No & 93 & 69.9 \\
\hline \multicolumn{3}{|l|}{ Waiting time: } \\
\hline One hour < & 84 & 65.1 \\
\hline One hour $>$ & 45 & 34.9 \\
\hline \multicolumn{3}{|l|}{ Type of basic insurance: } \\
\hline MSIO* & 1 & 0.7 \\
\hline $\mathrm{SSO} * *$ & 45 & 33.1 \\
\hline Rural & 62 & 45.6 \\
\hline Others & 27 & 19.9 \\
\hline Without insurance & 1 & 0.7 \\
\hline \multicolumn{3}{|l|}{ Supplement insurance: } \\
\hline Yes & 17 & 15.0 \\
\hline No & 96 & 85.0 \\
\hline \multicolumn{3}{|l|}{ Enrolled with family practitioner: } \\
\hline Yes & 128 & 94.1 \\
\hline No & 8 & 5.9 \\
\hline \multicolumn{3}{|l|}{ Type of family practitioner: } \\
\hline Urban & 69 & 53.1 \\
\hline Rural & 61 & 46.9 \\
\hline \multicolumn{3}{|l|}{ Satisfaction with family practitioner: } \\
\hline Yes & 79 & 63.7 \\
\hline No & 45 & 36.4 \\
\hline \multicolumn{3}{|l|}{$\begin{array}{l}\text { Visiting family practitioner before } \\
\text { attending hospital: }\end{array}$} \\
\hline Yes & 55 & 44.0 \\
\hline No & 70 & 56.0 \\
\hline \multicolumn{3}{|l|}{ Carrying referral slip: } \\
\hline Yes & 40 & 29.4 \\
\hline No & 96 & 70.6 \\
\hline
\end{tabular}


As the above table reveals, most of the respondents were characterized as not scheduling an appointment, with waiting time less than 1 hour at hospital before getting any care, with severity of disease equal to moderate and slight, and basic insurance but without supplement insurance, enrolled and satisfied with family practitioner, not visiting family practitioner before attending hospital, and not carrying referral slip. Among the variables of Table 2, those which were significantly associated with carrying referral slip is presented in Table 3, as follows.

Table 3. Caretakers carrying referral slip and associated variables in a typical tertiary teaching hospital in Sari-Iran

\begin{tabular}{|c|c|c|c|c|}
\hline & & $\begin{array}{l}\text { Not carrying } \\
\text { referral slip }\end{array}$ & $\begin{array}{c}\text { Carrying } \\
\text { referral slip }\end{array}$ & $P$ value \\
\hline \multirow{3}{*}{ Type of care } & Inpatient & $52(54.2 \%)$ & $12(30.0 \%)$ & \multirow{3}{*}{0.008} \\
\hline & Outpatient & $44(45.8 \%)$ & $28(70.0 \%)$ & \\
\hline & Subtotal & $96(100 \%)$ & $40(100 \%)$ & \\
\hline \multirow{4}{*}{ Type of attending } & $\begin{array}{c}\text { Emergency by } \\
\text { ambulance }\end{array}$ & $6(6.2 \%)$ & $0(0.0 \%)$ & \multirow{4}{*}{0.029} \\
\hline & $\begin{array}{l}\text { Emergency without } \\
\text { ambulance }\end{array}$ & $47(49.0 \%)$ & $15(37.5 \%)$ & \\
\hline & Non urgent & $43(44.8 \%)$ & $25(62.5 \%)$ & \\
\hline & Subtotal & $96(100 \%)$ & $40(100 \%)$ & \\
\hline \multirow{4}{*}{ Arranging appointment } & Yes & $21(22.3 \%)$ & $19(48.7 \%)$ & \multirow{3}{*}{0.003} \\
\hline & No & $73(77.7 \%)$ & $20(51.3 \%)$ & \\
\hline & Subtotal & $94(100 \%)$ & $39(100 \%)$ & \\
\hline & Yes & $50(58.1 \%)$ & $29(76.3 \%)$ & \multirow{3}{*}{0.039} \\
\hline \multirow[t]{2}{*}{ Satisfaction with family practitioner } & No & $36(41.9 \%)$ & $9(23.9 \%)$ & \\
\hline & Subtotal & $86(100 \%)$ & $38(100 \%)$ & \\
\hline \multirow{3}{*}{$\begin{array}{l}\text { Visiting family practitioner before } \\
\text { attending hospital }\end{array}$} & Yes & $15(17.6 \%)$ & $40(100 \%)$ & \multirow{3}{*}{0.000} \\
\hline & No & $70(82.4 \%)$ & $0(0.0 \%)$ & \\
\hline & Subtotal & $(100 \%)$ & $(100 \%)$ & \\
\hline
\end{tabular}

As is shown in the table, among the variables being studied, 5 variables including type of care, type of hospital attending, arranging appointment before attending hospital, satisfaction with their family practitioner, and visiting family practitioner before attending hospital were significantly related to carrying or not carrying referral slip by caretakers.

\section{Discussion}

The results of the current cross-sectional study that has taken place in a tertiary education provincial hospital affiliated to Mazandaran University of Medical Sciences revealed that less than $30 \%$ of hospital attendees carried out a referral slip. Regardless of the underlying causes of such situation (2), it was interpreted as the dysfunction of referral system in Iran's pyramidal DHS system. Where, theoretically, a well functioning referral system is fundamental to primary healthcare delivery $(7,9)$, but the dysfunction of referral systems are frequently mentioned in different studies $(10,7,2)$. This situation has different consequences for health system in total. It is actually an inappropriate use of limited health resources in a country like Iran that suffers seriously from the shortage of financial and health system resources. Indeed, as a concern of trend in health expenditure in 
Iran (18), major reforms in national health care system in recent years have directly and indirectly emphasized implementing referral system for better financial and nonfinancial achievement. Actually, the issue of cost containment continues to dominate the debate regarding the strategies for organizing and financing healthcare services across the world (19). Iran is already a relatively big spender in the region, and also by global standards. At $7.8 \%$ of GDP, Iran is comparable to a higherincome OECD range country. Nevertheless, a range of issues remain (8). Recent reforms in Iran's healthcare system have involved primary care facilities by introducing Family Practitioners (FPs) as gatekeepers, and hospitals as major providers of secondary care to play as referral facilities, and public health insurance companies of MSIO and SSO as key health insurance organizations for reconditioning referral guidelines when they come to reimburse both primary and secondary healthcare providers. Effective gatekeeping leads to a greater range of conditions to be managed by FPs at the point of first contact (20, $21,22)$, which could then be an appropriate and economically sound intervention to address both financial and nonfinancial issues. Gatekeeping modifies the patient care process with more first contact with a family practitioner and, consequently, less self-referral to secondary care services (18). But the results of the present study revealed that, currently, Iran's healthcare system is far from the point to achieve such advantage of a referral-based DHS. This situation (the dysfunction of referral system), is likely due to deficiencies in the components of the referral system, consisting community, physical infrastructure, healthcare providers, various communication systems, management information system, resources (financial and otherwise), and the administration and organization of the system (2).

In the present study, it was also found that some of the variables, such as type of care required or sort of attending the hospital in terms of urgency, as well as some attributes of FP, were related to patient going through referral pathway. In this regard, a report in the United States highlighted that $75 \%$ of the variation in referral rates for specific conditions is attributable to the characteristics of the presenting problem (23). In addition, other studies indicated that improved access to FPs and gatekeeping function reduced hospital referral and led to less hospitalization $(24,25$, 26), less utilization of specialist and emergency centers $(27,28)$, and less chance of being subject to inappropriate health interventions (29). Shifting care across specialist-family practice and secondary-primary care boundaries is possible and has shown to be cost-effective without adverse effect on health outcomes. For instance, family practitioners in Norway led hospitals to provide healthcare at lower cost compared with alternative modes of care (30). Several UK studies confirm cost-saving effect of FP hospitals by reducing referrals and admissions to higher-cost general hospitals staffed by hospital specialists $(31,32,33)$. Care delivered by family practitioners as compared with hospital specialists in hospital-based accident and emergency departments is shown to be more cost effective, with lower use of diagnostic investigations, lower referral rates to secondary services, lower prescription levels 
and no significant difference in patient satisfaction or health outcomes $(34,35,36)$.

Except for a small number of variables, as pointed out, the remaining socioeconomic and caretakers characteristics were not related to referral pattern of patients attending specialist hospitals studied in this investigation. Bypassing referral system from a wide range of population into a specialist teaching hospital happened where nearly all patients have already been covered by a capitation-based FPs. This could be interpreted as deficiencies in the components of referral system in Iran (2), and the deficiencies that have been felt by FPs in previous study in the same province (13-15, 37). Dealing with such fundamental problems requires appropriate and systematic consideration rather than segmental deficient interventions with poor infrastructural requirement (2). In fact, many primary healthcare programs in low-income countries have been unsuccessful due to their lack of necessary adequacy (38).

A national study of the referral practices of the US physicians showed that paying physicians by capitation did not influence referral rates, although it was associated with more referrals made for discretionary indications (39). Structural weaknesses in the organization of service delivery need to be addressed by developing more effective interface between the sub-systems of the health sector to enhance integration and continuum of care. There is a need to develop transparent referral criteria which can later be incorporated into clinical care guidelines to encourage management of health problems at PHC level and reduce unnecessary referrals to hospitals. This is critical to effective functioning of PHC to realize efficiency gains and to improve quality. The gatekeeping function of PHC must be strengthened by limiting access to secondary care only after referral by a named family physicians or general practitioner. There is good experience from countries that have welldeveloped PHC systems (such as England and the Netherlands) where strong gatekeeping function has been established. This will also help to enhance continuity of care and improve the ability of PHC level to co-ordinate optimally the patient's journey through the health system (18).

The results of the present study, as being presented and discusses, could be evidence that the most expensive and potentially valuable health facilities in Iran are not used rationally. The economic cost of such utilization both for caretakers and healthcare delivery system is very high. This is happening where the major health reforms in Iran particularly emphasized the implementation of referral system in using hospital facilities in recent years, and accordingly, substantial resources are capitated to primary healthcare physicians at the first level of healthcare delivery system. Given the findings of the current study and taking into account the newly introduced reforms in different components of Iran's healthcare system, together with available and relevant literature, a full revision of current reforms and appropriate remedy for deficiencies in the components of referral system in Iran is in top priority toward better achievement of desired health system goals and outcomes. 


\section{Limitations of the study}

The current study was carried out in a relatively well-off province that could influence the health seeking behavior of patients at referral hospitals. In improving the referral pattern and then making the utilization of specialist facilities more economical and rational, other issues, such as the quality of primary healthcare and family medicine itself, the budgeting and payment mechanisms in hospitals, the role of insurance companies in reimbursing hospitals, have crucial roles that were not taken into account in the present study.

\section{Acknowledgement}

The study was approved (Number: 16) and partially funded by research authorities at Mazandaran University of Medical Sciences. The authors thank deputy for research and technology at Mazandaran University of Medical Sciences and its student research committee for all their support and assistance. Also, we appreciate the collaboration of all respondents and staff at Imam Khomeini Teaching Hospital during the data collection.

\section{Conflict of interest}

Authors do not recognize any conflict of interest with individual, profession or organization.

\section{References}

1. Jackman, D., Myrick, F., Yonge, OJ. Rural nursing in Canada: a voice unheard. Online Journal of Rural Nursing and Health Care 2010; 10(1): 60-9.

2. WHO. Regional Office for the Eastern Mediterranean. The work of WHO in the Eastern Mediterranean region: annual report of the regional director 2014/ Regional Office for the Eastern Mediterranean Office. Cairo.
3. Low A., De Coeyere D., Shivute N., Brandt J L. Patient referral pattern in Namibia: identification of potential to improve the efficieny of the health care system. Int J Health Plann Mgmt. 2001; 16: 243-257.

4. Keating, L. N., Gandhi, K. T., Orav J., Bates W. D., John Z. Ayanian Z. J. Patient characteristics and experiences associated with trust in specialist physicians. Arch Intern Med. 2004; 164(9):1015-1020.

5. Kim Cervantes, René Salgado, Misun Choi, and Henry D. Kalter. Rapid Assessment of Referral Care Systems: A Guide for Program Managers. Published by the Basic Support for Institutionalizing Child Survival Project (BASICS II) for the United States Agency for International Development. Arlington, Virginia, November 2003.

6. Ilboudo et al. Assessment of providers' referral decisions in Rural Burkina Faso: a retrospective analysis of medical records. BMC Health Services Research. 2012; 12: 54.

7. Bossyns P, Abache R, Abdoulaye MS et al. 2006. Monitoring the referral system through benchmarking in rural Niger: an evaluation of the functional relation between health centres and the district hospital. BMC Health Services Research 6: 51.

8. DCPP. 2007. The critical role of district hospitals. Online at: http://www. dcp2. org/ file/ 78/DCPP-DistrictHospitals.pdf.

9. Gérvas J., Fernández P M. Western European best practice in primary healthcare. European Journal of General Practice. 2006; 12: 30-33.

10.Ilboudo et al., Compliance with referral for curative care in rural Burkina Faso, Health Policy and Planning 2012; 27:256-264 doi: 10.1093/heapol/czr041

11.DCP2: Primary Health Care. Keys to Delivering Cost-Effective Interventions. 2007. [http://www. dcp2.org].

12.Baggett P. D., O'Connell J. J., Singer E. D., Rigotti A. N. The unmet health needs of homeless adults: a national study. American Journal of Public Health. 2010; 100(7): 13261333.

13. Rouhani S., Akbarzadeh F. The Impact of Change of Payment Mechanism on the 
Performance of Rural Health Centers in Ambulatory Care under Family Medicine Scheme in Sari and Jouybar/ J Mazand Univ Med Sci, 2013; 23(Supple 1): 96-103 (Persian).

14.Rouhani S., Mohammadpour RA. Family medicine and patients' satisfaction in Iran, Life Science Journal 2012; 9(3): 1840-1847.

15.Rouhani S., Abdollahi F., Mohammadpour RA. The Association between Family SocioEconomic Status and Health Care Utilization in Ghaemshahr-Mazandaran, Iran, Iranian Journal of Health Sciences 2014; 2(2): 52-58.

16.Rouhani, S., Yazdani Charati, J., Mohammadpour, RA. Structural Quality \& utilizing outpatient Curative Care under Family Medicine Scheme in Rural Areas of Mazandaran -Iran, Iranian journal of health sciences 2013; 1(2): 28-34.

17.Imison C., Naylor C. Referral management. 2010. The King's Fund. UK.

18.The World Bank Group. 2008. Islamic Republic of Iran, Health Sector Review. Volume I, Main Report. Report No.: 39970 - IR.

19.Vinjar Fønnebø V., Grimsgaard S., Walach H., Ritenbaugh C., Norheim R.J., MacPherson H., Lewith G., Launs $\varnothing$ L., Koithan M., Falkenberg T., Boon H., Aickin M. Researching complementary and alternative treatments - the gatekeepers are not at home. BMC Medical Research Methodology. 2007; 7:7. doi:10.1186/1471-2288-7-7

20.Boerma G. W. W. Profiles of General Practice in Europe. 2003. Twin Design. The Netherlands Available from: http://www.nivel.nl

21.Starfield B., Lemke W.K., Bernhardt T., Foldes S.S., Forrest B.C., Weiner P.J. Comorbidity: Implications for the Importance of Primary Care in 'Case' Management Ann Fam Med 2003;1:814. DOI: $10.1370 / \mathrm{afm} .1$

22.Forrest CB, Nutting P, Starfield B, von Schrader S, Rohde C. 2003. Managed health plan effects on the specialty referral process: results from the ASPN referral study. Med Care 2003; 41: 242253.

23.Forrest CB, Reid RJ. 2001. Prevalence of health problems and primary care physicians' specialty referral decisions. J Fam Pract 2001; 50: 427432.
24.Saultz W.J. Defining and Measuring Interpersonal Continuity of Care. Ann Fam Med 2003; 1:134-143. DOI: 10:1370/afm.23.

25.Escarce J.J., Kapur, K., Joyce F.G., Van Vorst A.K. Medical care expenditures under gatekeeper and point-of-service arrangements. HSR: Health Services Research. 2001; 36 (6), Part I: 1037-1057.

26.Zweifel P., Breyer F. Health Economics, Oxford University Press, 2009. New York.

27.Afilalo J., Marinovich A., Afilalo M., Colacone B., Giguere C., Unger B. Nonurgent emergency department patient characteristics and barriers to primary care, ACAD EMERG MED. 2004; 11(12):

1302-1310. DOI:10.1197/j.aem.2004.08.032

28.Ferris G.T., Chang Y., Blumenthal D., Pearson D. S. Leaving gatekeeping behind - Effects of opening access to specialists for adults in a health maintenance organization. N Engl J Med. 2001; 345:1312-1317. DOI:10.1056/ NEJMsa 010097

29. Basu J., Friedman B., Burstin H. Primary Care, HMO Enrollment, and Hospitalization for Ambulatory Care Sensitive Conditions: A New Approach Medical care. 2002; 40(12): 12601269.

30.Pashen D., Chater B., Murray R., Sheedy V., White C., Eriksson L., De La Rue S., Du Rietz $M$. The expanding role of the rural generalist in Australia- A systematic review. 2007. Australian Primary Health Care Research Institute.

31. Oreilly J., Lowson K., Green J., Young B.J., Forster A. Post-acute care for older people in community hospitals - a cost-effectiveness analysis within a multi-centre randomised controlled trial. Age and Ageing 2008; 37: 513520.

32.Tucker J.H. Integrated Care: The Presence, Nature and Development of Integrated Care in Community Health Services in England and Ireland. 2012. Ph.D Thesis. University of Warwick Medical School. UK.

33.Hakkaart-vanRoijen L., Moll van Charante E.P., Bindels P., Yzermans C.J., Rutten F.F.H: A cost study of a general practitioner hospital in the Netherlands. European Journal of General Practice. 2004, 10: 45-49. 
34.Woods D. M., Kirk D., Agarwal S., Annandale E., Arthur T., Harvey J., Hsu R., Katbamna S., Olsen R., Smith L., Riley R., Sutton A. Vulnerable groups and access to health care: a critical interpretive review. National Coordinating Centre for NHS Service Delivery and Organisation R \& D (NCCSDO). 2005.

35.Leibowitza R., Dayb S., Duntb D. A systematic review of the effect of different models of afterhours primary medical care services on clinical outcome, medical workload, and patient and GP satisfaction. Family Practice. 2003; 20 (3): 311317.

36.van Uden J.T.C., Giesen H.J.P., Metsemakers F.M.J. Grol P.T.M.R. Development of Out-ofHours Primary Care by General Practitioners
(GPs) in The Netherlands: From Small-call Rotations to Large-scale GP Cooperatives. International Family Medicine 2006; 38 (8): 565-569.

37.Rouhani S., Bagher M. Experience of Family Physicians in Rural Areas Regarding Referral System and Improving it (A qualitative study), J Mazandaran Univ Med Sci 2015; 25(132): 1-13 (Persian).

38.Peterse I, Swartz L. Primary health care in the era of HIV/AIDS. Some implications for health systems reform. Soc Sci Med 2002; 55(6): 1005 13.

39.McKinlay J.B., Marceau L.D. The end of the golden age of doctoring, International Journal of Health Services. 2002; 32(2): 379-416. 